\title{
Study of fruit and vegetable intake in breast cancer patients in the city of Sabzevar
}

\author{
Akram Kooshki ${ }^{1}$, Manidgeh Yousefi Moghaddam², Roya Akbarzadeh ${ }^{3}$
}

${ }^{1}$ Ph.D. of Nutrition, Associate Professor, Department of Nutrition and Biochemistry, School of Medicine, Sabzevar University of Medical Sciences, Sabzevar, Iran

${ }^{2}$ Ph.D. of Anesthesiology, Assistant Professor, Department of Anesthesiologist, School of Medicine, Sabzevar University of Medical Sciences, Sabzevar, Iran

${ }^{3}$ M.Sc. of Nursing, Department of Operating Room \& Anesthesiology, School of Paramedic, Sabzevar University of Medical Sciences, Sabzevar, Iran

\section{Type of article: Original}

\begin{abstract}
Introduction: Diet is one of the most important modifiable risk factors for prevention and control of chronic diseases, including breast cancer. This study aimed to determine the fruit and vegetable intake in women with cancer breast in Sabzevar.

Methods: This cross-sectional study was conducted on 125 women with breast cancer in Sabzevar in 2011. Census sampling was done on volunteers in a visiting home and suspected women referred to the mammography, ultrasound, and radiology clinic in the Sabzevar center for breast cancer. Demographic and semi quantitative food questionnaires of 160 foods were completed for each of the patients by trained interviewers. Data were analyzed using the software Nutritionist IV. Descriptive statistics, one-sample t-test, and Chi-square test were used, employing the SPSS version 16.

Results: In this study, 125 women were assessed with breast cancer. The highest risk with breast cancer was $35.5 \%$ in women 40 to 49 years old. The results of this study showed that patients with breast cancer had minimum daily recommended intake ( $3.06 \pm 2.3$ serving of fruits and $2.09 \pm 1.81$ serving of vegetables in days). One sample t-test showed that the mean intake of fruits and vegetables was not a significant deference with daily recommended intake $(\mathrm{p}>0.05)$. The chi-square test showed that patients with minimum daily recommended intake of fruits and vegetables were at high risk for breast cancer in comparison with those who received the highest amount $(\mathrm{p}=0.001)$.
\end{abstract}

Conclusion: This study supports evidence that high vegetable and fruit intake is associated with lower breast cancer risk.

Keywords: Breast cancer, Fruits, Vegetables

\section{Introduction}

Breast cancer, with more than 1 million new cases per year is the most common cancer among women. The cancer is allocated in the highest rank among the most common cancers. Thus $21.4 \%$ of all tumors in women are breast cancer, and more than $8 \%-9 \%$ of women once in their lives experience breast cancer. According to these data, breast cancer is in fifth place among neoplasm (1). Researchers have identified several risk factors such as heredity, hormones, reproductive, and environmental factors, such as lifestyle and nutritional intake, are involved in the etiology of breast cancer $(2,3)$. Since at least one-third of neoplasm is associated with diet, it can be said that it is one of the most important modifiable risk factors for prevention and control of chronic disease, including breast cancer (4). If diagnosed early, the disease is considered a treatable cancer (5). Among food components, fruits and vegetables attract greater attention to reduce the risk of breast cancer. In several studies in the meta-analysis, the inverse association was observed between intake of fresh fruits and vegetables and risk of breast cancer $(6,7)$. Some

\section{Corresponding author:}

Roya Akbarzadeh, Department of Operating Room \& Anesthesia, School of Paramedic, Sabzevar University of Medical Sciences, Sabzevar, Iran. Tel: +98.5144446070, Email: roakbarzadeh53@gmail.com

Received: January 04, 2016, Accepted: June 18, 2016, Published: September 2016 iThenticate screening: June 18, 2016, English editing: July 28, 2016, Quality control: August 06, 2016

(C) 2016 The Authors. This is an open access article under the terms of the Creative Commons Attribution-NonCommercialNoDerivs License, which permits use and distribution in any medium, provided the original work is properly cited, the use is non-commercial and no modifications or adaptations are made. 
meta-analysis studies also showed no significant association between breast cancer and intake of fruits and vegetables $(8,9)$. According to epidemiological findings, there is a reverse relationship between the regular consumption of fruits and vegetables with reduced risk of breast cancer $(6,7)$. The fruits and vegetables have anticancer drugs such as vitamin $\mathrm{C}$, folate, fiber, carotenoids, phytosterols, flavonoids, and other phytochemicals and protease inhibitors. These functional nutrients reduce oxidative stress and reduce the oxidation of lipids and DNA damage caused by cell stimulation by inducing DNA repair enzymes involved in the repair process, thus reducing $\mathrm{PH}$ and increasing SCFA production. Protease inhibitors are also effective in the prevention of DNA damage and decrease the mutation $(9,10)$. It also should be noted that there is a high degree of correlation between food components that are synergistic, and antagonistic effects of nutrients and different food groups are going to affect the disease process. Thus, the methodological separation of the specific effects of food is a serious problem. Given the increasing prevalence of breast cancer in Iran and the lack of sufficient certainty about the impact of fresh fruits and vegetables to reduce the risk of breast cancer, this study aimed to determine the fruit and vegetable intake in women with breast cancer in Sabzevar.

\section{Material and Methods}

This cross-sectional study was conducted on women with breast cancer in the city of Sabzevar in 2011. Census sampling was done on volunteers in a visiting home and suspected women referred to the mammography, ultrasound, and radiology clinic in Sabzevar center for breast cancer. We recruited those subjects whose cancer was recognized without having another disease, taking only cancer drugs, not taking food complements, and not having an unusual diet throughout the past year. After written informed consent was taken of patients, a semi-quantitative food frequency questionnaire about demographic characteristics and consisting of 60 food items were completed by an experienced interviewer. The height with tape and weight with Seca scale were measured, respectively, with 100 $\mathrm{g}$ and $1 \mathrm{~cm}$ recorded. Body mass index (BMI) using the formula weight (in kilograms) to squared height (in meters) was calculated. Food information was obtained using the Software Nutritionist IV. Descriptive statistics and a onesample t-test were used for comparison of mean intake of vegetables and fruits with daily recommended intake, and a chi-square test was used for comparison of frequency of patients with breast cancer in deference levels of fruits and vegetables intake. The data were analyzed by software SPSS version 16 (SPSS Inc., Chicago, Illinois, USA). This study was approved by the Research Ethics Committee of Sabzevar University of Medical Sciences.

\section{Results}

In this study, 125 women were assessed with breast cancer. The youngest woman was reported to be 28 years old and the oldest was 86 years old (50.7 \pm 1$)$. Seventy-four percent of women were city dwellers, and $61 \%$ were born in rural areas. The mean of menopause age was $46.7 \pm 4.7$ years; the menarche age was $13.2 \pm 1.6$ years and BMI $\left(\mathrm{kg} / \mathrm{m}^{2}\right) 22.5 \pm 5.7$. The highest risk with cancer breast was $35.5 \%$ in women 40 to 49 years old. The mean of fruit intake was $3.06 \pm 2.3$ and vegetables $2.09 \pm 1.8$. Sixty percent of women had an intake of fruits less than two servings daily, and $83.2 \%$ women had an intake of vegetables of less than three servings daily. Statistical analysis by t-test showed that the mean intake of fruits and vegetables was not a significant deference with daily recommended intake ( $>0.05$ ). The chi-square test showed that patients with a minimum daily recommended intake of fruits and vegetables were a high risk for breast cancer in comparison with those who received the highest amount $(\mathrm{p}=0.001)$.

\section{Discussion}

The results of this study showed that patients with breast cancer had minimum daily recommended intake (three to five serving/days of fruit and two to four serving/days of vegetables). This study showed that breast cancer risk in people who consume more than two servings of fruit and a vegetable intake of more than three servings in a day was less than those who consume fruits and vegetables less than two to three servings per day, respectively. Results of the study were consistent with previous studies, and the hypothesis is that lower consumption of fruits and vegetables increases the risk of breast cancer (7-9). Freudenheim and colleagues showed a strong correlation between reducing the risk of breast cancer and vegetable intake and found no relationship between breast cancer risk and fruit intake (11). In contrast, Lisowska indicated to reduce the risk of breast cancer by increasing the intake of fruit versus a lower intake (12). Zhang et al. also showed that women who received the highest amount of vegetables and fruit, $72 \%$ and $47 \%$ had a lower risk of breast cancer, respectively (13). Worth noting is that reducing the risk of breast cancer has been seen by increasing $45 \%$ vegetables and $43 \%$ intake of fruits in Thai women (14). In addition, Bao and colleagues have reported the reduction the risk of breast cancer among Chinese women who had consumed high acidy fruits and vegetables (15). In a meta-analysis conducted in 2010, an inverse relationship between a healthy diet rich in fruits and vegetables with a lower risk of breast cancer (16). In the cohort design of a Singapore Chinese cohort, a trend of decreasing risk breast cancer with increasing fruits, vegetables, and soy was observed 
among postmenopausal women, and the assumption is that having special dietary factors played a role in protecting against breast cancer $(17,18)$. In a pooled analysis performed on 993,466 women from 20 prospective studies, it was observed that there is a significant association between total fruits and vegetables consumption and breast cancer risk. Vegetable consumption demonstrated a significant correlation, but fruit consumption alone was not signi ficant (9). Olsen's study showed that the risk of breast cancer in women who consumed more than 570 grams of fruits and vegetables a day was half that of the women who consumed less than 255 grams per day, although the association was not significant for fruit and vegetables alone (19). Case-control studies also showed that reducing the risk of breast cancer and fruit and vegetable consumption is associated with the receptors (20), with $31 \%$ and $35 \%$ reduction in estrogen receptors $(\mathrm{ER}+)$ breast cancer in the highest intake compared with lower fruit and vegetable intake (21). In contrast, in a pooled analysis on eight prospective studies in Western societies, any protective effect of fruit and vegetable consumption has been observed to lower breast cancer risk (22). Several factors may be involved. The type and amount of fruits and vegetables are different in different countries, a lack of diversity of fruits and vegetables consumption can affect different populations, sample size, study design, confounding variables, etc. Kubatka et al. found the effect of anti-cancer phytochemical Flavin in fruits in suppressing tumors (23). Suzuki et al. found, with a 10-year study on 47,289 Japanese women, that consumption of vegetables in the cabbage family has a significant inverse association with breast cancer in postmenopausal women (24). Cabbage family vegetables, due to the active ingredient benzyl isothiocyanate, reduced certain non-estrogen-dependent cancer cell growth without weight loss or other side effects (25). Oxidative stress has a recognized role in carcinogenesis. Examples of biomolecules such as DNA damaged by reactive oxygen and antioxidants can neutralize their effect. Fruits and vegetables due to antioxidants and expression of catalase genotype (CAT) have an inverse relationship with breast cancer risk in consumers (26). On the other hand, Pierce and colleagues' study of 3088 women, aged 18-70 years old found that diets high in vegetables, fruits, and fiber and low in fat showed no reduction risk of breast cancer or death in women with breast cancer at an early stage (25).

\section{Conclusions}

The present findings indicate that greater intake of vegetables and fruits is associated with a lower risk of breast cancer in women. Also consumption of fruits and vegetables in the daily diet is emphasized for prevention and control of breast cancer. If further studies are confirmed, the results can have a significant public implication as a diet rich in vegetables and fruits could become an inexpensive means for targeting breast cancer risk.

\section{Acknowledgments:}

The authors offer thanks to all respected patients who patiently responded to the questions. This project was financially supported by the Deputy of Research, Sabzevar University of Medical Sciences.

\section{Conflict of Interest:}

There is no conflict of interest to be declared.

\section{Authors' contributions:}

All authors contributed to this project and article equally. All authors read and approved the final manuscript.

\section{References:}

1) Kooshki A, Akbarzadeh R. Assesment of calcium, Vitamin D and dairy products intake in patients with breast cancer. IJOGI. 2014; 17(101): 13-8.

2) Barnett GC, Shah M, Redman K, Easton DF, Ponder BA, Pharoah PD. Risk factors for the incidence of breast cancer: do they effect survival from the disease? J Clin Oncol. 2008; 26(20): 3310-6. doi: 10.1200/JCO.2006.10.3168. PMID: 18612147.

3) Akbarzadeh R, Ghardashi F, Kooshki A, Tabaraei R, Hashemian M, Noroozinegad T, et al. Individual characteristics, family history and blood group in with breast cancer in sabzevar. J Sabzevar Uni Med Sci. 2014; 20(5): 582-9.

4) Cannon G. Translating science into improved health. Forum Nutr. 2003; 56: 186-7. PMID: 15806855.

5) Moatamed N, Hadi N, Talei A. Some risk factors of breast cancer in women more than 35 years old in Shiraz. J Zanjan Uni Med sci. 2004; 12: 25-33.

6) Kruk J. Association between vegetable, fruit and carbohydrate intake and breast cancer risk in relation to physical activity. Asian Pac J Cancer Prev. 2014; 15(11): 4429-36. doi: 10.73147. PMID: 24969864.

7) Aune D, Chan DS, Vieira AR, Rosenblatt DA, Vieira R, Greenwood DC, et al. Fruits, vegetables and breast cancer risk: a systematic review and meta-analysis of prospective studies. Breast Cancer Res Treat. 2012; 134(2): 479-93. doi: 10.1007/s10549-012-2118-1. PMID: 22706630. 
8) Dragsted LO, Krath B, Ravn-Haren G, Vogel UB, Vinggaard AM, Bo Jensen P, et al. Biological effects of fruit and vegetables. Proc Nutr Soc. 2006; 65(1): 61-7. doi: 10.1079/PNS2005480. PMID: 16441945.

9) Jung S, Spiegelman D, Baglietto L, Bernstein L, Boggs DA, van den Brandt PA, et al. Fruit and vegetable intake and risk of breast cancer by hormone receptor status. J Natl Cancer Inst. 2013; 105(3): 219-36. doi: 10.1093/jnci/djs635. PMID: 23349252, PMCID: PMC3593764.

10) Burrows CJ, Muller JG. Oxidative nucleobase modifications leading to strand scission. Chem Rev. 1998; 98(3): 1109-52. doi: 10.1021/cr960421s. PMID: 11848927.

11) Freudenheim JL, Marshall JR, Vena JE, Laughlin R, Brasure JR, Swanson MK, et al. Premonopausal breast cancer risk and intake of vegetables fruits and related nutrients. J Natl Cancer Inst. 1996; 88(6): 340-8. PMID: 8609642.

12) Lissowska J, Gaudet MM, Brinton LA, Peplonska B, Sherman M, Szeszenia-Dabrowska N, et al. Intake of fruits and vegetables in relation to breast cancer by hormone receptor status. Breast Cancer Res Treat. 2008; 107(1): 113-7. doi: 10.1007/s10549-007-9524-9. PMID: 17318377.

13) Zhang CX, Ho SC, Chen YM, Fu JH, Cheng SZ, Lin FY. Greater vegetable and fruit intake is associated with a lower risk of breast cancer among Chinese women. Int J Cancer. 2009; 125(1): 181-8. doi: 10.1002/ijc.24358. PMID: 19358284.

14) Sangrajrang S, Chaiwerawattana A, Ploysawang P, Nooklang K, Jamsri P, Somharnwong S. Obesity, diet and physical inactivity and risk of breast cancer in Thai women. Asian Pac J Cancer Prev. 2013; 14(11): 7023-7. doi: 10.7314/APJCP.2013.14.11.7023. PMID: 24377643.

15) Bao PP, Shu XO, Zheng Y, Cai H, Ruan ZX, Gu K, et al. Fruit, vegetable, and animal food intake and breast cancer risk by hormone receptor status. Nutr Cancer. 2012; 64(6): 806-19. doi: 10.1080/01635581.2012.707277. PMID: 22860889, PMCID: PMC3758811.

16) Brennan SF, Cantwell MM, Cardwell CR, Velentzis LS, Woodside JV. Dietary patterns and breast cancer risk: a systematic review and meta-analysis. Am J ClinNutr. 2010; 91(5): 1294-302. doi: 10.3945/ajen.2009.28796. PMID: 20219961.

17) Jin Z, MacDonald RS. Soy isoflavones increase latency of spontaneous mammary tumors in mice. J Nutr. 2002; 132(10): 3186-90. PMID: 12368416.

18) Constantinou AI, Krygier AE, Mehta RR. Genistein induces maturation of cultured human breast cancer cells and prevents tumor growth in nude mice. Am J Clin Nutr. 1998; 68(6suppl): 1426-30. PMID: 9848511.

19) Olsen A, Tjønneland A, Thomsen BL, Loft S, Stripp C, Overvad K, et al. Fruits and vegetables intake differentially affects estrogen receptor negative and positive breast cancer incidence rates. J Nutr. 2003; 133(7): 2342-7. PMID: 12840204

20) Gaudet MM, Britton JA, Kabat GC, Steck-Scott S, Eng SM, Teitelbaum SL, et al. Fruits, vegetables, and micronutrients in relation to breast cancer modified by menopause and hormone receptor status. Cancer Epidemiol Biomarkers Prev. 2004; 13(9): 1485-94. PMID: 15342450.

21) Hislop TG, Kan L, Coldman AJ, Band RR, Brauer G. Influence of estrogen receptor status on dietary risk factors for breast cancer. CMAJ. 1988; 138(5): 424-30. PMID: 3342359, PMCID: PMC1267662.

22) Smith-Warner SA, Spiegelman D, Yaun SS, Adami HO, Beeson WL, van den Brandt PA, et al. Intake of fruits and vegetables and risk of breast cancer: a pooled analysis of cohort studies. JAMA. 2001; 285(6): 769-76. doi: 10.1001/jama.285.6.769. PMID: 11176915.

23) Kubatka P, Kapinová A, Kello M, Kruzliak P, Kajo K, Výbohová D, et al. Fruit peel polyphenols demonstrate substantial anti-tumour effects in the model of breast cancer. Eur J Nutr. 2016; 55(3): 955-65. doi: 10.1007/s00394-015-0910-5. PMID: 25930965.

24) Suzuki R, Iwasaki M, Hara A, Inoue M, Sasazuki S, Sawada N, et al. Fruit and vegetable intake and breast cancer risk defined by estrogen and progesterone receptor status: the Japan Public Health Center-based Prospective Study. Cancer Causes Control. 2013; 24(12): 2117-28. doi: 10.1007/s10552-013-0289-7. PMID: 24091793.

25) Pierce JP, Natarajan L, Caan BJ, Parker BA, Greenberg ER, Flatt SW, et al. Influence of a diet very high in vegetables, fruit, and fiber and low in fat on prognosis following treatment for breast cancer: the Women's Healthy Eating and Living (WHEL) randomized trial. JAMA. 2007; 298(3): 289-98. doi: 10.1001/jama.298.3.289. PMID: 17635889, PMCID: PMC2083253.

26) Ahn J, Gammon MD, Santella RM, Gaudet MM, Britton JA, Teitelbaum SL, et al. Associations between Breast Cancer Risk and the Catalase Genotype, Fruitand Vegetable Consumption, and Supplement Use. Am J of Epidemiol. 2005; 162(10): 943-52. doi: 10.1093/aje/kwi306. PMID: 16192345. 